\section{Policies and managerial guidelines for national cancer control programs $^{1}$}

Key words: cancer, disease control and prevention, health care economics and organizations, program development, public health.

\footnotetext{
1 Based on: 1) World Health Organization. Executive summary: national cancer control programmes: policies and managerial guidelines. Geneva: WHO; 2002. Available from:. http://www.who.int/ cancer. Accessed 23 September 2002. 2) World Health Organization. New cancer report offers hope for patients and communities [press release]. Geneva: WHO; 2002. Available from: http://www.who.int. Accessed 1 July 2002.
}

Millions of lives could be saved each year if countries made use of existing knowledge and the best cost-effective methods to prevent and treat cancer, according to a new report from the World Health Organization (WHO). Entitled National Cancer Control Programs: Policies and Managerial Guidelines, the WHO report says that one-third of the 10 million new cases of cancer that are diagnosed globally every year can be prevented and that another third can be effectively treated if there is early detection and treatment. For the last third of cases, suffering can be greatly relieved through effective palliative care.

Regardless of the resource constraints that a country faces, a well-conceived, well-managed program can improve the national situation as well as the lives of those living with cancer. In many cases, primary prevention, early detection, and palliative care are neglected in favor of treatment-oriented approaches, regardless of whether these approaches are actually cost-effective or whether they improve patients' quality of life.

\section{THE BURDEN OF CANCER}

Although cancer has often been regarded principally as a problem of the developed world, of the 10 million new cancer cases each year, 5.5 million of them are in developing countries. Every year, there are more than 6 million cancer deaths, accounting for $12 \%$ of all deaths in the world. Over the next 20 years, the number of cancer deaths annually will rise to some 10 million. Contributing to this projected increase in deaths are the growing proportion of elderly people in the world, in whom cancer occurs more frequently than in the young; an overall decrease in deaths from communicable diseases; the decline in some countries in mortality from cardiovascular diseases; and the rising incidence of certain forms of cancer, especially lung cancer resulting from tobacco use.

Among men, lung and stomach cancer are the most common cancers worldwide, while prostate cancer is largely seen in more-developed countries. For women, the most common cancers worldwide are breast and cervical cancer, although cervical cancer is primarily seen in less-developed countries. Lung, colorectal, and stomach cancer are among the five most common cancers for both men and women, in both industrialized and developing countries. 


\section{THE NATURE OF CANCER}

Cancer arises principally as a consequence of exposure of individuals to carcinogenic agents in what they inhale or eat and drink, or through exposures at their work or elsewhere. Rather than inherited genetic characteristics, other factors play the major roles in the etiology of cancer. These include personal habits such as tobacco use and dietary patterns, occupational exposure to carcinogens, and biological factors such as viral hepatitis B infection and human papillomavirus infection. Knowledge of many of these factors can serve as the basis of cancer control. Vaccination against hepatitis B, for instance, can protect against liver cancer.

Cancer is profoundly associated with social and economic status. Cancer risk factors are highest in groups with the least education. In addition, patients in the lower social classes have consistently poorer survival rates than do those in the higher social classes.

\section{THE ELEMENTS OF A CANCER CONTROL PROGRAM}

A national cancer control program is designed to reduce the incidence and mortality of cancer as well as to improve the quality of life of patients. A good program would assess how to best use available resources to achieve effective and equitable outcomes. This would mean finding the right balance among prevention, early detection, diagnosis and treatment, and palliation.

\section{Prevention}

Prevention involves eliminating or minimizing exposure to the causes of cancer as well as reducing individual susceptibility to the effects of such causes. This approach offers the greatest public health potential and the most cost-effective longterm cancer control prospects.

The present and potential burden of tobaccoinduced cancer is such that every country should give its highest priority to tobacco control in its fight against cancer. Tobacco use in all forms is responsible for about 30\% of all cancer deaths in developed countries, and this percentage is rising steadily in developing countries, particularly among women. The best approach to preventing tobacco-related cancer is preventing the uptake of tobacco. Tobacco is responsible for $80 \%-90 \%$ of all lung cancer deaths, and probably some of the deaths from cancer of the oral cavity, larynx, esophagus, and stomach.
Tobacco consumption can be reduced by a comprehensive strategy that includes legislative action to raise taxes on tobacco products and to limit access and promotion as well as smoking cessation programs and education for youth and adults in order to promote healthy lifestyles.

In recent years, substantial evidence has pointed to the link that overweight and obesity have to cancer of the esophagus, colorectum, breast, endometrium, and kidney. It is advisable for individuals to control their weight and avoid weight gain in adulthood by reducing caloric intake and by performing physical activity. The latter has a protective effect in reducing the risk of colorectal cancer. The composition of the diet is also important since eating fruits and vegetables may decrease the risk for oral, esophageal, gastric, and colorectal cancer. High consumption of preserved meat or red meat may be associated with an increased risk of colorectal cancer. Consuming large amounts of alcoholic beverages increases the risk of cancer of the oral cavity, pharynx, larynx, esophagus, liver, and breast.

Conducting a cancer prevention program within the context of an integrated noncommunicable disease prevention program is an effective national strategy. Tobacco use, alcohol, poor nutrition, physical inactivity, and obesity are risk factors common to other noncommunicable diseases such as cardiovascular disease, diabetes, and respiratory diseases.

Occupational and environmental exposure to a number of chemicals can cause cancer of a variety of sites; examples include mesothelial cancer (asbestos), bladder cancer (aniline dyes), and leukemia (benzene). A number of infections or infestations cause certain types of cancer: viral hepatitis B and C cause cancer of the liver, human papillomavirus infection causes cervical cancer, and the bacterium Helicobacter pylori increases the risk of stomach cancer. Exposure to ionizing radiation is also known to give rise to certain cancers, and excessive solar ultraviolet radiation increases the risk of all types of cancer of the skin. National policies and programs can be enacted to reduce exposure to these risks and implement preventive interventions. Care needs to be taken to ensure that the public has a clear understanding of these major risks and is not overwhelmed by the minor risks that are frequently described in the news media.

\section{Early detection}

Early detection comprises early diagnosis in symptomatic populations and screening in asymptomatic at-risk populations. Increasing awareness of the signs and symptoms of cancer contributes to detection of the disease in less-advanced stages. 
Where tests for cancer of specific sites are available and facilities are appropriate, screening of apparently healthy individuals can disclose cancer in early or precursor stages, when treatment may be most effective.

With early detection, there is a greater chance that curative treatment will be successful, particularly for cancers of the breast, cervix, mouth, larynx, colon and rectum, and skin. It is therefore critical that people are taught to recognize early warning signs of the disease, such as lumps, sores that fail to heal, abnormal bleeding, persistent indigestion, and chronic hoarseness, and are urged to seek prompt medical attention. This can be promoted by public health education campaigns and through the training of primary health care workers.

Another approach to early detection is population screening, with the mass application of simple tests to identify individuals with asymptomatic disease. However, screening programs should be undertaken only when their effectiveness has been demonstrated; when personnel, equipment, and other resources are sufficient to cover nearly all of the target group; when facilities exist for confirming diagnoses and for treatment and follow-up of those with abnormal results; and when prevalence of the disease is high enough to justify the effort and costs of screening.

At present, in countries with high levels of resources, screening can be advocated only for cancer of the breast and cervix. Efforts should concentrate on women at greatest risk of developing invasive cancer: those aged 35 years and over for cervical cancer and those aged over 50 years for breast cancer. In developing countries, organized screening should only be considered for cervical cancer. It should focus primarily on providing a limited number of screenings with maximum population coverage, because the women at greatest risk for cervical cancer are in general the last to approach the health care system.

\section{Diagnosis and treatment}

Cancer diagnosis is the first step to cancer management. This calls for a combination of careful clinical assessment and diagnostic investigations that include endoscopy, imaging, histopathology, cytology, and laboratory studies.

The primary objectives of cancer treatment are cure, prolongation of life, and improvement of the quality of life. A national cancer control program should establish guidelines for integrating treatment resources with programs for early detection, and the program should provide therapeutic standards for the most important cancers in the country.
Care of cancer patients typically starts with recognition of an abnormality, followed by consultation at a health care facility with appropriate services for diagnosis and treatment. Treatment may involve surgery, radiation therapy, chemotherapy, hormonal therapy, or some combination of these.

Optimal treatment of people diagnosed with certain types of cancer detected early, such as cancers of the uterine cervix and corpus, breast, testis, and melanoma, will result in five-year survival rates of $75 \%$ or more. In contrast, survival rates in patients with cancer of the pancreas, liver, stomach, and lung are generally less than $15 \%$. Some treatments require sophisticated technology that is available only in locations with substantial resources. Since the cost of establishing and maintaining such facilities is high, they should initially be concentrated in a relatively few places in a country, to avoid draining resources that could be devoted to other components of the national cancer control program. Facilities can be expanded when additional resources are available.

\section{Palliative care}

Despite advances in prevention and treatment, the majority of people diagnosed with cancer will, at some stage, need palliative care. A comprehensive approach to palliative care should embrace the psychological, emotional, and spiritual needs of the patient and also take into account the needs of family and caregivers.

Improved quality of life is of paramount importance to patients with cancer. Pain relief and palliative care can be provided relatively simply and inexpensively. These services should be available in every country and should be given high priority, especially in developing countries, where cure of the majority of cancer patients is likely to remain beyond reach for years to come. Health workers and family caregivers can be trained to deliver palliative care effectively. Primary health care settings can respond to the majority of patients' needs. In addition, in many developing countries with poor infrastructure, home-based care will make an essential contribution to achieving the necessary coverage.

\section{MANAGING NATIONAL CONTROL PROGRAMS}

Although it is clear that objectives and priorities need to be tailored to the specific country context, the planning processes to be undertaken in all countries should follow four basic steps: 1 ) assess- 
ing the magnitude of the cancer problem, 2) setting measurable control objectives, 3) evaluating possible, evidence-based strategies for cancer prevention and control, and 4) choosing priorities for initial cancer control activities. Gauging the magnitude of the cancer problem requires analyzing the cancer burden and risk factors as well as assessing capacity in terms of facilities, personnel, programs, and services. The strategies chosen must be feasible as well as acceptable and relevant to the society. Priority areas should be classified into two groups: activities that can be introduced or improved without the need for additional resources, and activities that will require extra resources.

A flexible approach is needed, as political, socioeconomic, and epidemiological situations can evolve over time and can vary within a country. With this in mind, three separate scenarios are provided to help guide countries toward what is possible in line with their level of resources: low, medium, or high. The scenarios can also be used to identify specific actions relevant to regions or different population groups within a nation.

\section{A low level of resources}

This scenario refers to low-income countries where resources for chronic disease are completely absent or very limited. Many such countries may have great political and social instability. A considerable proportion of the population is rural. Infant and adult mortality rates are high. Communicable diseases and malnutrition are a major cause of morbidity and mortality, especially for children. Life expectancy is relatively low. Cancer is not one of the main health problems, but it can be one of the leading causes of death among those over 15 years of age. The majority of cancer patients are diagnosed in an advanced stage. Exposure to cancer risk factors such as tobacco or environmental carcinogens other than aflatoxin may be low but almost invariably rising. Exposure to infectious causes of cancer will usually be high (human papillomaviruses and hepatitis B virus, and sometimes schistosomiasis). Health care services are often delivered by informal means, and alternative medicine is a major component. Infrastructure and human resources for cancer prevention or control are nonexistent or very limited in quantity, quality, and accessibility.

In such circumstances, the first step is to establish a basis for prevention of cancer and other chronic diseases by limiting the extent to which the health scourges of the industrialized worldtobacco use and the "Western diet" — can enter the country and add to existing health problems. The general public and health care workers can be made aware of the early warning signs of cancer and other diseases. This will ensure that cases are identified, referred, and treated early in the course of disease, before they become advanced and incurable. National diagnostic and treatment guidelines should be developed, in order to establish a minimum standard of care and to promote the rational use of existing resources as well as equitable access to the limited treatment resources. A national cancer control program should also establish a basis for pain relief and palliative care of individuals with advanced disease, to ensure that they maintain their quality of life as much as possible.

\section{A medium level of resources}

In countries with a medium level of resources, the majority of the population is urban, and life expectancy is over 60 years. The country has been through the epidemiological transition, and cancer is usually one of the leading causes of disease and mortality. There is a high exposure to risk factors, especially tobacco, improper diet, infectious agents, and carcinogens in the workplace. While infrastructure and human resources for developing cancer prevention and control activities are available, there are limitations in quantity, quality, and accessibility. There are weaknesses in organization, prioritysetting, resource allocation, and information systems for adequate monitoring and evaluation. Primary prevention and early detection are usually neglected in favor of treatment-oriented approaches, without much concern regarding their cost-effectiveness.

In general, the primary prevention activities needed in this type of setting are tobacco control, reduction of alcohol use, and promotion of healthy diet and physical exercise. Special attention should be paid to carcinogens in the workplace as well as human papillomavirus and other infectious agents. Awareness of the warning signs for the common cancers should be promoted. If rates of cervical cancer are high, the highest priority for a screening program is cervical cytology screening, focusing mainly on covering a high proportion of the women at risk. Screening for other types of cancers should be discouraged. Cancer treatment should focus on cancers that are curable, and clinical trials should be encouraged to evaluate lower-cost approaches that eventually can be provided to all patients irrespective of their socioeconomic condition. Moresophisticated approaches, such as radiotherapy and chemotherapy, should be introduced in specialized centers. Major efforts should be made to achieve the highest coverage for pain relief and palliative care, 
using low-cost drugs (e.g., oral morphine) and other interventions.

\section{A high level of resources}

In industrialized countries with a relatively high level of resources for health care, life expectancy is over 70 years, and cancer is a major cause of death for both men and women. Many elements of a cancer control program are in place, but they may not be well integrated into a comprehensive national system. Further, coverage of the population may be uneven, with particular groups such as those in rural areas, indigenous people, and recent immigrants having difficulty accessing services. There may also be serious deficiencies with respect to providing easy access to pain relief and palliative care services.

Reorganizing the system could lead to greater cost-effectiveness and improved reach and acceptability of services. Comprehensive health promotion programs, including in schools and workplaces, should be implemented.

There should be a concerted effort to promote awareness of the early warning signs for cancer. However, national screening programs should generally only be implemented for cervical and breast cancer, since screening for other cancers has not yet been proven to be cost-effective. Implementing a comprehensive surveillance system can ensure a rapid response to changes in disease patterns and to weaknesses in service provision.

Printed copies of the report can be ordered from the World Health Organization, from: WHO Marketing and Dissemination, CH-1211 Geneva 27, Switzerland; fax: 412279148 57; telephone: 4122 79124 76; e-mail: bookorders@who.int; Internet: http:/ / www.who.int/pub/en. The cost of the report is Swiss francs 42 (US\$37.80), with a price of Sw.fr. 29.40 for clients in developing countries. The report is now available only in English, but WHO is preparing editions in Spanish and in French as well.

Copies of the full report can also be downloaded for free from the WHO Web site, at http:// www.who.int/cancer. That Web site also has an executive summary of the report available in English, Spanish, or French.

In the near future, WHO plans to produce a second volume of the report that will focus more on the "how-to" aspects of developing comprehensive operational models to implement the report's recommendations.

\section{SINOPSIS}

\section{Estrategias y directrices de gestión para los programas nacionales de lucha contra el cáncer}

Según un nuevo informe de la Organización Mundial de la Salud titulado Programas nacionales de lucha contra el cáncer: estrategias y directrices de gestión, cada año se podrían salvar millones de vidas si los países hicieran uso de los conocimientos existentes y de los métodos más rentables de prevención y tratamiento del cáncer. El informe afirma que un tercio de los 10 millones de nuevos casos de cáncer que se registran cada año en el mundo son prevenibles y que otro tercio se podría tratar eficazmente si se diagnosticara $y$ tratara precozmente. En el tercio restante se puede reducir mucho el sufrimiento gracias al tratamiento paliativo. Un programa nacional eficaz de lucha contra el cáncer debe encontrar el equilibrio adecuado entre las actividades de prevención, detección precoz, diagnóstico, tratamiento y paliación. Los procesos de planificación deberían seguir en todos los países cuatro pasos básicos: 1) evaluación de la magnitud del problema; 2) fijación de objetivos de control medibles; 3) evaluación de posibles estrategias de prevención y control basadas en datos objetivos, y 4) elección de prioridades para las actividades iniciales de lucha contra el cáncer. Es necesario un enfoque flexible, dado que las situaciones políticas, socioeconómicas y epidemiológicas de un país pueden evolucionar y cambiar con el tiempo. El informe proporciona tres escenarios distintos para guiar a los países hacia la consecución de objetivos dentro de las posibilidades acordes con sus recursos: bajos, medios o altos. Estos escenarios pueden servir también para identificar acciones específicas pertinentes para diferentes regiones o grupos de población de un mismo país. 